\title{
A novel mode of control of Mycoplasma pneumoniae HPr kinase/phosphatase activity reflects its parasitic lifestyle
}

\author{
Katrin Steinhauer, Tanja Jepp, Wolfgang Hillen and Jörg Stülke
}

Author for correspondence: Tel: +499131 8528818. Fax: +4991318528082.

e-mail: jstuelke@biologie.uni-erlangen.de

Lehrstuhl für Mikrobiologie, Institut für Mikrobiologie, Biochemie und Genetik der Friedrich-AlexanderUniversität ErlangenNürnberg, Staudtstr. 5, D-91058 Erlangen, Germany

\begin{abstract}
Among the few regulatory proteins encoded by Mycoplasma pneumoniae is HPr kinase/phosphatase (HPrK/P), the key regulator of carbon metabolism in low-GC Gram-positive bacteria. The corresponding gene, hprK, and the gene encoding the target protein $\mathrm{HPr}$, ptsH, were overexpressed. In vitro analysis of the purified proteins confirmed ATP-dependent phosphorylation of HPr by HPrK/P. In contrast to HPrK/P of Bacillus subtilis, which is by default a phosphatase and needs high ATP concentrations for kinase activity, the $M$. pneumoniae enzyme exhibits kinase activity at very low ATP concentrations and depends on $P_{i}$ for phosphatase activity. This inverted control of enzymic activity may result from the adaptation to very different ecological niches. While the standard activities of HPrK/P from M. pneumoniae and other Grampositive bacteria differ, they are both modulated by the concentration of ATP, $P_{i}$ and glycolytic intermediates. Site-directed mutagenesis of a potential ATPbinding site and of the HPrK/P signature sequence resulted in four different activity classes: (i) inactive proteins, (ii) enzymes with reduced kinase and phosphatase activities, (iii) enzymes that had lost phosphatase, but not kinase activity, and (iv) enzymes that exhibited increased phosphatase activity.
\end{abstract}

Keywords: phosphorylation, Walker A box, mutagenesis, catabolite repression

\section{INTRODUCTION}

Mycoplasmas are pathogens of mammals that cause respiratory and urogenital diseases. They belong to the low-GC Gram-positive bacteria, even though they lack a cell wall (Woese, 1987). Their parasitic lifestyle is reflected by the fact that they contain the smallest genomes of any self-replicating organisms known so far (Razin et al., 1998). Over the past years, mycoplasmas have attracted considerable and growing interest owing to three considerations: (i) to understand the biology of an important pathogen (Razin et al., 1998); (ii) to identify the minimum genetic equipment necessary for independent cellular life and to construct such minimal genomes (Hutchinson et al., 1999); and (iii) to develop and refine methodology in the post-genomic era, such as proteomics and transcriptomics (Balasubramanian et al., 2000; Wasinger et al., 2000; Weiner et al., 2000).

Abbreviations: PTS, phosphoenolpyruvate: sugar phosphotransferase system; HPr, histidine-containing phosphocarrier protein of the PTS; HPrK/P, HPr kinase/phosphatase; FBP, fructose 1,6-bisphosphate.
We are interested in the control of carbon catabolism in the human pathogen Mycoplasma pneumoniae. This bacterium contains a small genome of about $816 \mathrm{~kb}$ (Himmelreich et al., 1996). The metabolic capacities of M. pneumoniae are rather limited. There are enzymes of the phosphoenolpyruvate:sugar phosphotransferase system (PTS) required for the transport of glucose, fructose and mannitol and all the enzymes of the glycolytic pathway. Glycerol and glycerol 3-phosphate may be transported by the glycerol facilitator and an ABC-type transporter, respectively, and are further catabolized by glycolysis. In contrast, the enzyme complement for the pentose-phosphate pathway is incomplete. Since M. pneumoniae lacks enzymes for the tricarboxylic acid cycle, quinones and cytochromes, ATP generation is restricted to substrate-level phosphorylation (Razin et al., 1998; Himmelreich et al., 1996; Miles, 1992). In addition to carbohydrates, $M$. pneumoniae can probably catabolize arginine, yielding ammonia and ATP (Himmelreich et al., 1996).

Knowledge of the regulation of carbon catabolism in $M$. pneumoniae and other mollicutes is very limited. The complete genome of $M$. pneumoniae encodes only a few 
regulatory proteins. Two-component systems or alternative sigma factors commonly found in other bacteria are absent (Himmelreich et al., 1996; Himmelreich et al., 1997). M. pneumoniae and Mycoplasma genitalium encode an HPr kinase/phosphatase (HPrK/P), the key regulatory enzyme of carbon catabolism in low-GC Gram-positive bacteria (Himmelreich et al., 1996; Fraser et al., 1995). Moreover, $\mathrm{HPrK} / \mathrm{P}$ activity is also present in mollicutes such as Mycoplasma capricolum and Acholeplasma laidlawii (Hoischen et al., 1993; Zhu et al., 1997). In Bacillus subtilis, HPrK/P senses the metabolic state of the cell and reversibly phosphorylates HPr of the PTS and an HPr homologue, Crh, at seryl residues (Galinier et al., 1997, 1998; Reizer et al., 1998). HPr-Ser-P and Crh-Ser-P serve as cofactors for the transcriptional regulator, CcpA. HPr-Ser-P is a poor substrate for phosphorylation by Enzyme I of the PTS (Galinier et al., 1997; Reizer et al., 1998; Deutscher et al., 1995). The regulatory consequences of HPr phosphorylation by $\mathrm{HPrK} / \mathrm{P}$ have been reviewed in detail (Stülke \& Hillen, 1999). The presence of an $h p r K$ gene in M. pneumoniae and other mollicutes suggests that carbon metabolism in these bacteria may be governed by this master regulator. The assumed involvement of $\mathrm{HPrK} / \mathrm{P}$ in regulation of carbon and energy metabolism is reinforced by the accumulation of fructose 1,6bisphosphate (FBP), a trigger of HPr kinase activity in $B$. subtilis, in glycolytically active cells of Mycoplasma gallisepticum (Reizer et al., 1998; Egan et al., 1986; Mason et al., 1981).

We have studied the activity of HPrK/P isolated from M. pneumoniae. Our results demonstrate that the protein has both kinase and phosphatase activities. In contrast to $\mathrm{HPrK} / \mathrm{P}$ of $B$. subtilis which is active as a phosphatase in the absence of any metabolic intermediates, the M. pneumoniae enzyme exhibits kinase activity. The activity of the protein in vivo, and thus the phosphorylation state of HPr, is adjusted by the ratio of ATP, FBP and $P_{i}$. Mutagenesis experiments indicate that a conserved Walker A box nucleotide-binding motif and the conserved HPr kinase signature sequence (Reizer et al., 1998) are required for both activities. Several mutations in the nucleotide-binding motif of $\mathrm{HPrK} / \mathrm{P}$ completely eliminate phosphatase activity without affecting the kinase activity.

\section{METHODS}

Bacterial strains and growth conditions. Escherichia coli DH5 $\alpha$ (Sambrook et al., 1989) was used for cloning experiments and overexpression of recombinant proteins. The cells were grown in LB medium and transformants were selected on plates containing ampicillin $\left(100 \mu \mathrm{g} \mathrm{ml}^{-1}\right)$.

DNA manipulation and plasmid constructions. Transformation of E. coli and plasmid DNA extraction were performed using standard procedures (Sambrook et al., 1989). Restriction enzymes, T4 DNA ligase and DNA polymerase were used as recommended by the manufacturers. DNA fragments were purified from agarose gels using a Nucleotrap Gel Extraction kit (Macherey \& Nagel). DNA sequences were determined using the dideoxy chain-termination method (Sambrook et al., 1989).
To overexpress the wild-type HPrK/P protein as well as the $\mathrm{HPr}$ protein fused to a hexahistidine sequence at the $\mathrm{N}$ terminus, plasmids were constructed as follows. DNA fragments corresponding to the $h p r K$ and $p t s H$ ORFs, respectively, were amplified by PCR using the cosmids G07 and D09 bearing the M. pneumoniae $h p r K$ and $p t s H$ sequences (Himmelreich et al., 1996). The primer pair used for amplification of the $h p r K$ gene was KS9 (5'-AAAGTCGACATGA AAAAGTTATTAGTCAAGGAG-3') and KS10 (5'-ATTAA GCTTGGTCTGCTACTAACACTAGGATTCAT CTTTT TTACG-3'). The primers used for amplification of the $p t s H$ gene were KS 34 (5'-AAAGTCGACATGAAGAAGATTCAA GTAGTCGTTAAAGAC-3') and KS 35 (5'-AAAAAGCTTT TAAATAACTTGGTGTTTTTCTAAAACTGC- $3^{\prime}$ ). The PCR products were digested with SalI and HindIII, and the resulting fragments were cloned into the expression vector pWH844 (Schirmer et al., 1997) cut with the same enzymes. The resulting plasmids were pGP204 (for $h p r K$ ) and pGP217 (for $p t s H)$.

Site-directed mutagenesis of the M. pneumoniae $h p r K$ gene was performed by a two-step PCR approach as described previously (Hanson et al., 2002). The mutant alleles were cloned into pWH844 as described for the wild-type.

Protein purification. E. coli $\mathrm{DH} 5 \alpha$ was used as host for the overexpression of recombinant proteins. Expression was induced by the addition of IPTG (final concentration $1 \mathrm{mM}$ ) to exponentially growing cultures $\left(\mathrm{OD}_{600} 0 \cdot 8\right)$. Cells were lysed using sonication $\left(8 \times 30 \mathrm{~s}, 4^{\circ} \mathrm{C}, 50 \mathrm{~W}\right)$ or a French press cell $(2000$ p.s.i. $=13.8 \mathrm{MPa})$. After lysis the crude extracts were centrifuged at $15000 \mathrm{~g}$ for $30 \mathrm{~min}$. For purification of the $\mathrm{HPrK} / \mathrm{P}$ proteins the resulting supernatants were passed over a $\mathrm{Ni}^{2+}$ HiTrap chelating column (Pharmacia) followed by elution with an imidazole gradient (in a buffer containing $10 \mathrm{mM}$ Tris/HCl, pH 7.5, $200 \mathrm{mM} \mathrm{NaCl}$ ).

For the recombinant HPr protein the overproduced protein was detected in the pellet fraction of the lysate. Therefore, after centrifugation as described above, the supernatant was discarded and the pellet was resuspended using $6 \mathrm{M}$ urea. After an additional centrifugation of the resuspended pellet at $15000 \mathrm{~g}$ for $30 \mathrm{~min}$, the resulting supernatant containing the solubilized HPr protein was passed over the $\mathrm{Ni}^{2+}$ HiTrap chelating column (Pharmacia). The protein was renatured while attached to the column by using an extended wash-out, followed by elution via an imidazole gradient. Renaturation of the $\mathrm{HPr}$ was assayed by using it as a substrate for in vitro phosphorylation by Enzyme I and HPrK/P. Complete phosphorylation was taken as an indication that the renatured protein was present in a native form.

After elution the fractions were tested for the desired protein using $12.5 \%$ SDS-PAGE gels for HPrK/P and $10 \%$ Tris/ Tricine gels (Schägger \& von Jagow, 1987) for HPr. The relevant fractions were combined and dialysed overnight.

Purified proteins were concentrated using Microsep Microconcentrators with a molecular mass cut-off of 3 and $10 \mathrm{kDa}$ for $\mathrm{HPr}$ and $\mathrm{HPrK} / \mathrm{P}$, respectively (Pall Filtron). Protein concentration was determined according to the method of Bradford (1976) using the Bio-Rad dye-binding assay where bovine serum albumin served as the standard.

$\left(\mathrm{His}_{6}\right) \mathrm{HPr}$ and $\left(\mathrm{His}_{6}\right) \mathrm{HPrK} / \mathrm{P}$ of B. subtilis were purified as described previously (Hanson et al., 2002).

Activity assays of HPrK/P. Activity assays were carried out with purified $\mathrm{HPrK} / \mathrm{P}$ in assay buffer $\left(10 \mathrm{mM} \mathrm{MgCl}_{2}, 25 \mathrm{mM}\right.$ Tris/HCl, $\mathrm{pH} 7 \cdot 6,1 \mathrm{mM}$ dithiothreitol) using purified $\left(\mathrm{His}_{6}\right) \mathrm{HPr}$ or $\left(\mathrm{His}_{6}\right) \mathrm{HPr}$-Ser-P. ATP, potassium phosphate and FBP were added as indicated. The assays were carried out at 
$37^{\circ} \mathrm{C}$ for $15 \mathrm{~min}$ followed by thermal inactivation of the enzyme $\left(4 \mathrm{~min}\right.$ at $\left.95^{\circ} \mathrm{C}\right)$. The assay mixtures were analysed on $10 \%$ native polyacrylamide gels as described previously (Hanson et al., 2002). Proteins were visualized by Coomassie staining.

For the radioactive assay, $\mathrm{HPrK} / \mathrm{P}$ activity was determined in a mixture containing $10 \mathrm{mM} \mathrm{MgCl}_{2}, 25 \mathrm{mM}$ Tris $/ \mathrm{HCl}$, $\mathrm{pH} 7 \cdot 6,1 \mathrm{mM}$ dithiothreitol, $0 \cdot 1 \mathrm{mM}\left[\gamma^{32}\right.$-P $]$ ATP $(0 \cdot 8 \mu \mathrm{Ci}$ $\mathrm{nmol}^{-1}$ ), $20 \mathrm{mM} \mathrm{FBP}$ and purified $\left(\mathrm{His}_{6}\right) \mathrm{HPr}$ from M. pneumoniae or HPr from Bacillus megaterium in a volume of $20 \mu \mathrm{l}$. Incubation was performed for $15 \mathrm{~min}$ at $37^{\circ} \mathrm{C}$. The reaction was stopped by adding $5 \mu$ l SDS 'quenching buffer' (Reizer $e t$ al., 1998) followed by boiling for $3 \mathrm{~min}$. Proteins were separated by SDS-PAGE on a $15 \%$ gel. HPr-Ser- ${ }^{32} \mathrm{P}$ was analysed by autoradiography using the TINA software of a Phosphoimager (Fujifilm BAS 1500).

$\left(\mathrm{His}_{6}\right)$ HPr-Ser-P of M. pneumoniae was prepared as follows. After incubation of purified $\left(\mathrm{His}_{6}\right) \mathrm{HPr}$ with $\mathrm{HPr}$ kinase in assay buffer in the presence of $10 \mathrm{mM}$ ATP and $20 \mathrm{mM}$ FBP the enzyme was thermally inactivated. The reaction led to complete phosphorylation of $\left(\mathrm{His}_{6}\right) \mathrm{HPr}$ which was confirmed on a $10 \%$ native gel. To separate the phosphorylated protein from low-molecular-mass effector molecules used in the phosphorylation reaction, the assay mixture was passed over a HiTrap Desalting column (Sephadex G25, Pharmacia). $\left(\mathrm{His}_{6}\right)$ HPr-Ser-P of B. subtilis was prepared as described previously (Hanson et al., 2002).

\section{RESULTS}

\section{Purification of $M$. pneumoniae HPr and HPrK/P}

The M. pneumoniae HPr (NCBI NP_109741) and HPrK/P (NCBI NP_109911) proteins were identified in the course of the sequencing of the M. pneumoniae genome (Himmelreich et al., 1996). To assess the activities of $\mathrm{HPr}$ and HPrK/P from M. pneumoniae the corresponding genes were cloned into the expression vector pWH844, allowing the expression and purification of the proteins carrying an $\mathrm{N}$-terminal hexahistidine sequence (see Methods). Cloning and expression of the M. pneumoniae proteins was facilitated by the fact that both the $p t s H$ and $h p r K$ genes do not contain UGA triplets (which encode tryptophan in $M$. pneumoniae, but are used as stop codons in E. coli). The recombinant proteins were purified to apparent homogeneity by Ni-NTA affinity chromatography.

$\mathrm{His}_{6}$-HPr was phosphorylated by Enzyme I and HPrK/P in a phosphoenolpyruvate or ATP-dependent manner, respectively (data not shown). $\mathrm{His}_{6}-\mathrm{HPr}$ was also recognized by polyclonal antibodies raised against $\mathrm{HPr}$ from B. megaterium (data not shown). The purified $\mathrm{His}_{6}-\mathrm{HPrK} / \mathrm{P}$ in vitro phosphorylated $\mathrm{HPr}$ from $B$. megaterium and M. pneumoniae; however, the efficiency of phosphorylation was about 20-fold higher for the cognate HPr (data not shown).

\section{Regulation of kinase activity of $M$. pneumoniae HPrK/P}

The effect of increasing concentrations of ATP on kinase activity of M. pneumoniae HPrK/P was tested. All HPr in the reaction was phosphorylated at ATP con- (a)

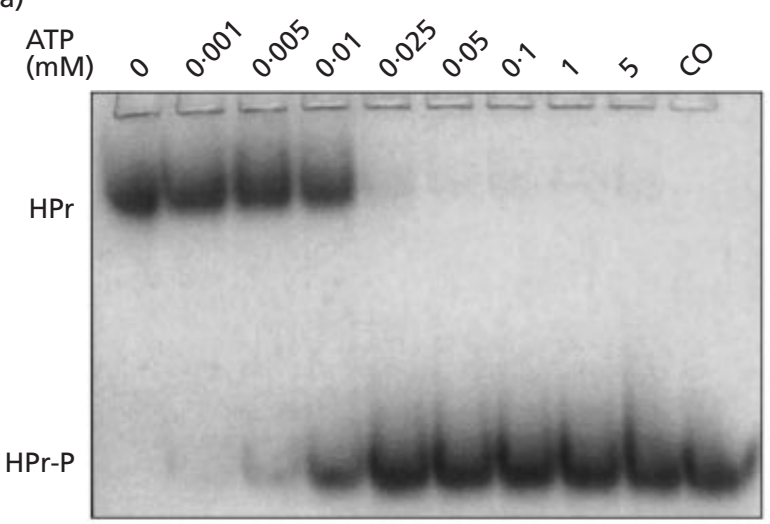

(b)

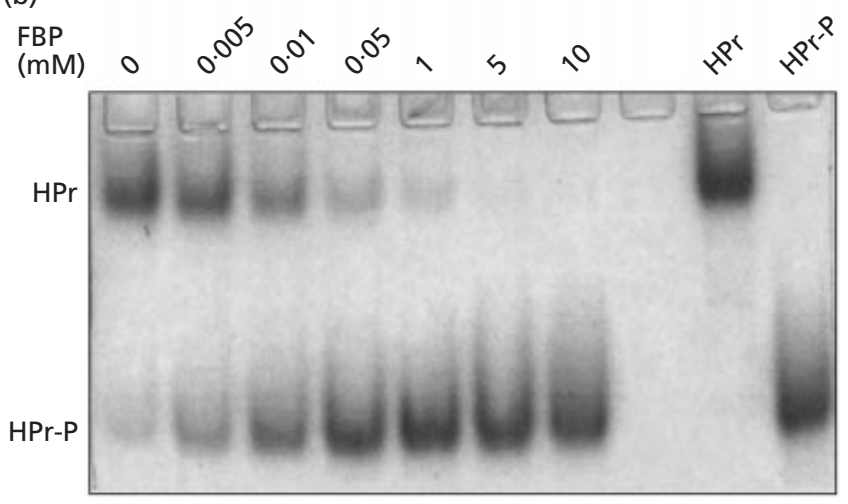

Fig. 1. Kinase activity of $M$. pneumoniae HPrK/P in the presence of various effectors. $M$. pneumoniae $H \operatorname{Pr}(20 \mu \mathrm{M})$ was incubated with HPrK/P (500 nM) in assay buffer in a final volume of $20 \mu \mathrm{l}$. After 15 min incubation at $37^{\circ} \mathrm{C}$, the enzyme was inactivated. The proteins were analysed using $10 \%$ native PAGE. (a) Effect of increasing ATP concentrations on HPr phosphorylation by HPrK/P. The control lane (CO) contains HPr(Ser-P). (b) Effect of increasing concentrations of FBP on kinase activity in the presence of $50 \mu \mathrm{M}$ ATP and $5 \mathrm{mM} \mathrm{P}$. The control lanes contain HPr and HPr(Ser-P).

centrations of $25 \mu \mathrm{M}$ and above. An ATP concentration as low as $1 \mu \mathrm{M}$ did yield kinase activity (note that ATP was the limiting component in this reaction) (Fig. 1a).

Kinase activity of some HPrK/P proteins, like that of $B$. subtilis and Lactobacillus casei, is stimulated by glycolytic intermediates such as FBP (Galinier et al., 1998; Reizer et al., 1998; Jault et al., 2000; Dossonnet et al., 2000). We analysed the response of the kinase activity of HPrK/P of $M$. pneumoniae to FBP in the presence of low ATP concentrations $(1,5$ and $10 \mu \mathrm{M})$. Even at the lowest ATP concentration tested, no stimulatory effect of FBP was observed (data not shown).

Both activities of HPrK/P may be controlled by the concentration of $\mathrm{P}_{\mathrm{i}}$, as shown for the enzyme from Enterococcus faecalis (Kravanja et al., 1999). The addition of $1 \mathrm{mM} P_{i}$ to the $M$. pneumoniae kinase reaction in the presence of $50 \mu \mathrm{M}$ ATP resulted in partial inhibition of kinase activity (data not shown). At $5 \mathrm{mM}$ $\mathrm{P}_{\mathrm{i}}$, kinase activity was completely inhibited (Fig. 1b). We investigated whether FBP as a major glycolytic 


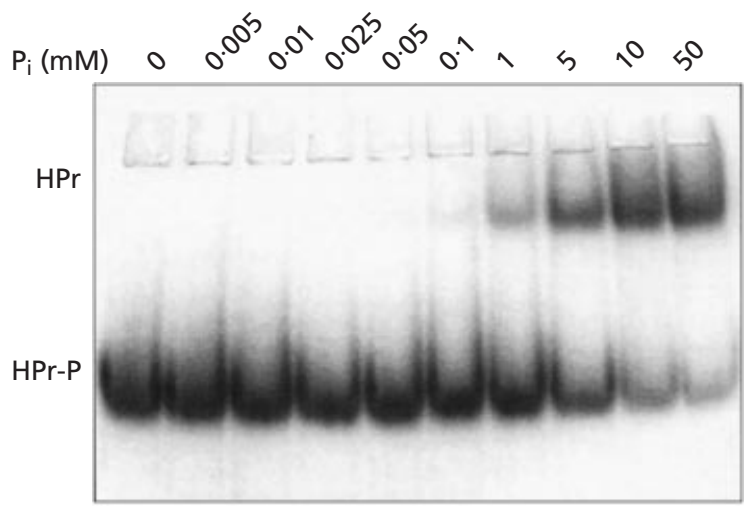

Fig. 2. Phosphatase activity of $M$. pneumoniae HPrK/P in the presence of increasing concentrations of $P_{i}$. HPr(Ser-P) $(20 \mu \mathrm{M})$ was incubated with HPrK/P (500 nM) in assay buffer to which increasing concentrations of $P_{i}$ were added as indicated. After 15 min of incubation at $37^{\circ} \mathrm{C}$, the enzyme was inactivated by heating at $95^{\circ} \mathrm{C}$ for $4 \mathrm{~min}$. The proteins were analysed using $10 \%$ native PAGE.

intermediate might counteract the inhibitory effect of $\mathrm{P}_{\mathrm{i}}$. Indeed, FBP prevented kinase inhibition by $\mathrm{P}_{\mathrm{i}}$ (see Fig. $1 b)$.

\section{Regulation of phosphatase activity of $M$. pneumoniae HPrK/P}

Phosphatase activity of $\mathrm{His}_{6}-\mathrm{HPrK} / \mathrm{P}$ from M. pneumoniae was analysed using $\mathrm{His}_{6}$-HPr-Ser-P from $M$. pneumoniae as a substrate. Significant phosphatase activity was detected only if the $\mathrm{P}_{\mathrm{i}}$ concentration in the reaction mixture exceeded $1 \mathrm{mM}$ (Fig. 2). The observed antagonistic effects between $\mathrm{FBP}$ and $\mathrm{P}_{\mathrm{i}}$ regarding kinase activity of $\mathrm{HPrK} / \mathrm{P}$ from other bacteria prompted us to investigate the influence of FBP on phosphatase activity as well. In the presence of $5 \mathrm{mM} \mathrm{P}_{\mathrm{i}}$, no effect of FBP on phosphatase activity was observed (data not shown). However, if ATP $(50 \mu \mathrm{M})$ was included in the assay mix, FBP shifted the activity towards the kinase reaction.

\section{Comparison of activities of HPrK/P from $M$. pneumoniae and $B$. subtilis}

The data presented above indicate that the HPrK/P of M. pneumoniae is active as a kinase at very low ATP concentration, irrespective of the presence or absence of FBP. In contrast, HPrK/P from B. subtilis was reported to exhibit kinase activity only at high ATP concentrations or at intermediate ATP concentrations in the presence of FBP (Jault et al., 2000). Thus, the $M$. pneumoniae enzyme may have an inverted default activity. To test whether this difference is significant we assayed both enzymic activities under physiological conditions $(5 \mathrm{mM} \mathrm{P}, 0.2$ or $2 \mathrm{mM} \mathrm{ATP}$, increasing amounts of FBP). The enzyme from B. subtilis has no kinase activity at $0 \cdot 2 \mathrm{mM}$ ATP and requires the presence of FBP (at least $10 \mathrm{mM}$, indicative of a high glycolytic activity) for kinase activity at $2 \mathrm{mM}$ ATP. In contrast, the M. pneumoniae HPrK/P exhibits kinase activity at low concentration of ATP (Fig. 3). As expected in the presence of $\mathrm{P}_{\mathrm{i}}$ (Jault et al., 2000), B. subtilis HPrK/P exhibits phosphatase activity in the presence of both low and high ATP concentrations. Only in the presence of high FBP concentrations, was inhibition of phosphatase activity observed (Fig. 4a). Again, the enzyme from $M$. pneumoniae shows a different pattern of activity: FBP was a very potent inhibitor of phosphatase activity, even
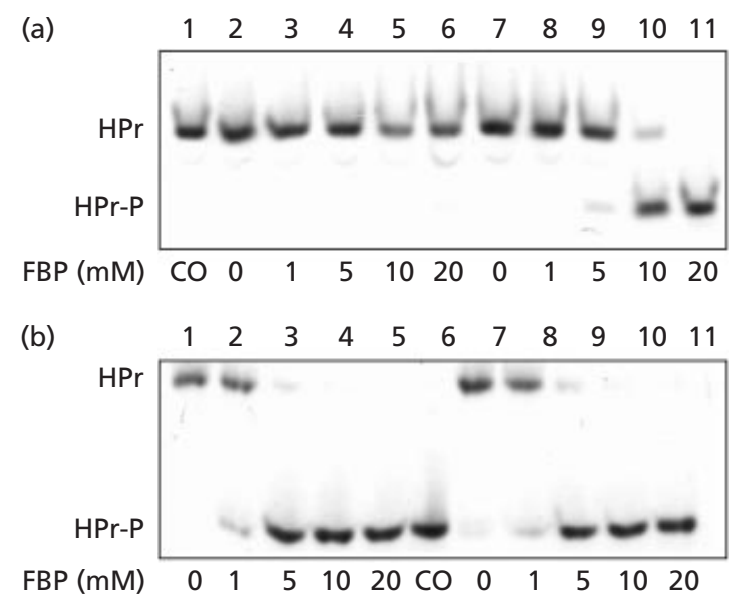

Fig. 3. Kinase activity of HPrK/P in the presence of various effectors. The assays were performed as described in the legend to Fig. 1. (a) Kinase activity of HPrK/P from B. subtilis in the presence of increasing FBP concentrations. The enzyme was incubated with HPr from $B$. subtilis. The control lane (CO) shows $B$. subtilis HPr. Lanes: 2-6, reactions contained $0.2 \mathrm{mM}$ ATP and $5 \mathrm{mM} \mathrm{P}$; 7-11, reactions contained $2 \mathrm{mM}$ ATP and $5 \mathrm{mM} \mathrm{P}_{\mathrm{i}}$. (b) Kinase activity of HPrK/P from $M$. pneumoniae in the presence of increasing FBP concentrations. The enzyme was incubated with $\mathrm{HPr}$ from $M$. pneumoniae. The control lane (CO) contains HPr(Ser-P). Lanes: 1-5, reactions contained 0.2 mM ATP and 5 mM $P_{i} ; 7-11$, reactions contained $2 \mathrm{mM}$ ATP and $5 \mathrm{mM} \mathrm{P}$. 

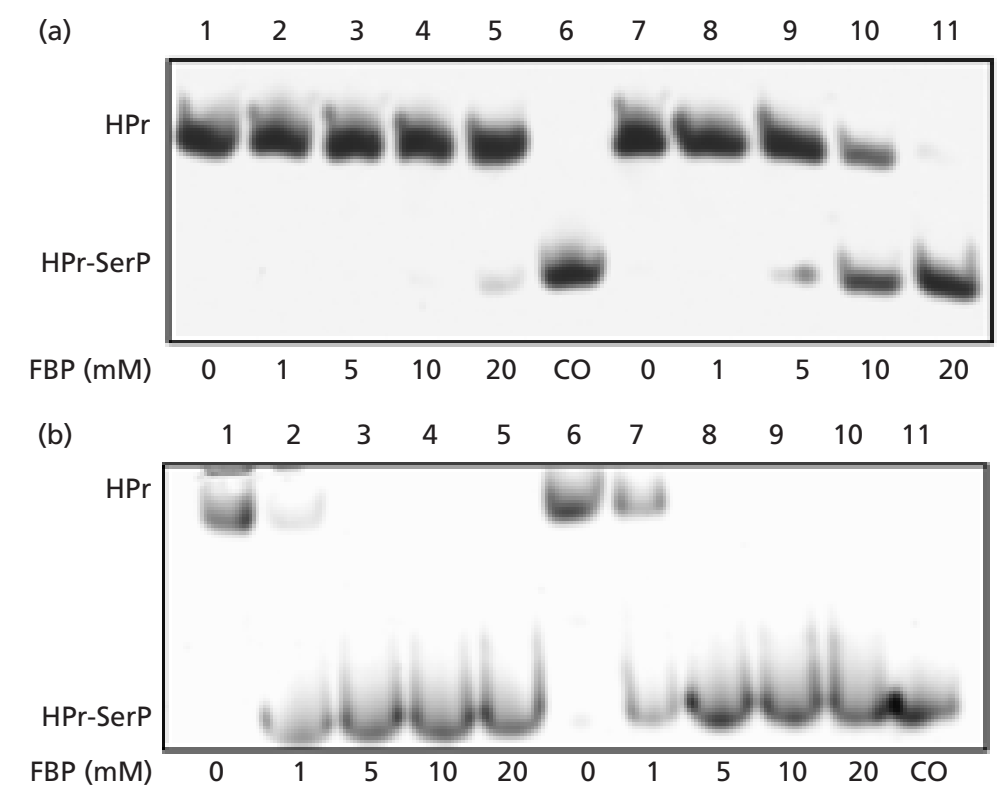

Fig. 4. Phosphatase activity of HPrK/P in the presence of various effectors. The assays were carried out under the same conditions as described in the legend to Fig. 1, except for the fact that the enzyme was incubated with HPr(Ser-P) instead of HPr. (a) Phosphatase activity of HPrK/P from B. subtilis in the presence of increasing FBP concentrations. The enzyme was incubated with $\mathrm{HPr}(\mathrm{Ser}-\mathrm{P})$ from $B$. subtilis. Lanes: $1-5$, reactions contained $0.2 \mathrm{mM}$ ATP and $5 \mathrm{mM} \mathrm{P}_{\mathrm{i}}$; 7-11, reactions contained $2 \mathrm{mM}$ ATP and $5 \mathrm{mM} \mathrm{P}$. The control lane (CO) shows HPr(Ser-P). (b) Phosphatase activity of HPrK/P from $M$. pneumoniae in the presence of increasing FBP concentrations. The enzyme was incubated with $H \operatorname{Pr}(\operatorname{Ser}-\mathrm{P})$ from $M$. pneumoniae. Lanes: $1-5$, reactions contained $0.2 \mathrm{mM}$ ATP and $5 \mathrm{mM} \mathrm{P}_{\mathrm{i}} ; 6-10$, reactions contained $2 \mathrm{mM}$ ATP and $5 \mathrm{mM}$ $\mathrm{P}_{\mathrm{i}}$. The control lane (CO) shows $\mathrm{HPr}(\mathrm{Ser}-\mathrm{P})$.

$1 \mathrm{mM}$ FBP resulted in complete and partial inhibition of phosphatase activity in the presence of either 0.2 or 2 mM ATP (Fig. 4b).

\section{Functional analysis of conserved regions of HPrK/P}

$\mathrm{HPrK} / \mathrm{P}$ of $\mathrm{M}$. pneumoniae shares two conserved regions with other members of this class of bifunctional protein kinases/phosphatases : the Walker A box nucleotide-binding site (Walker et al., 1982; Saraste et al., 1990; residues G154-E162) and the $\mathrm{HPrK} / \mathrm{P}$ specific signature sequence (Reizer et al., 1998; residues E202V211). We studied the functional importance of these regions by site-directed mutagenesis. Mutant alleles of $h p r K$ were constructed, and the resulting proteins were overexpressed and purified with an N-terminal hexahistidine sequence. The results of the activity assays are summarized in Fig. 5.

Two residues in the nucleotide-binding site were essential for both enzymic activities of $\mathrm{HPrK} / \mathrm{P}$. The corresponding mutations (G159A, K160A, K160R) completely prevented activity. Mutations of the two other universally conserved glycine residues in the Walker A box motif (G154A and G157A) resulted in a fourfold decrease of kinase activity in comparison to the wildtype protein under the conditions of assay. Moreover, kinase activity of these proteins was no longer regulated by $\mathrm{P}_{\mathrm{i}}$ and FBP. Both mutations also severely affected phosphatase activity: whereas the G154A exchange resulted in complete loss, the G157A mutant exhibited a very weak phosphatase activity. Mutations of S156, which is also strongly conserved in $\mathrm{HPrK} / \mathrm{P}$, had opposing effects. The S156A mutation did not affect kinase activity (Fig. 5), whereas the phosphatase activity was about fourfold greater than that of the wild-type enzyme. Interestingly, this mutant enzyme also showed an increased inhibition of kinase activity by $\mathrm{P}_{\mathrm{i}}$. By contrast, the S156T mutation led to a fourfold decrease of kinase and a complete loss of phosphatase activity. These findings suggest that the size of the amino acid at this position is important rather than the hydroxyl group. Based on studies with other ATP-binding proteins (Vertommen et al., 1996), S161 may be involved in $\mathrm{Mg}^{2+}$ binding. A mutation of this residue in $\mathrm{HPrK} / \mathrm{P}$ (S161A) resulted in a tenfold decrease of the kinase activity and abolished any phosphatase activity. Moreover, $\mathrm{P}_{\mathrm{i}}$ very efficiently inhibited the residual kinase activity of this mutant enzyme. An S161T mutation had less pronounced effects: the kinase activity was only slightly reduced, but phosphatase activity was barely detectable. The regulation of this mutant by $\mathrm{P}_{\mathrm{i}}$ and $\mathrm{FPB}$ was similar to that of the wild-type protein. Finally, an E162D mutant protein exhibited a constitutive kinase activity which was no longer inhibited by $\mathrm{P}_{\mathrm{i}}$. The E162D mutant protein did not show any phosphatase activity.

In addition to the three conserved glycine residues in the Walker A box motif, another universally conserved glycine was analysed by site-directed mutagenesis. 


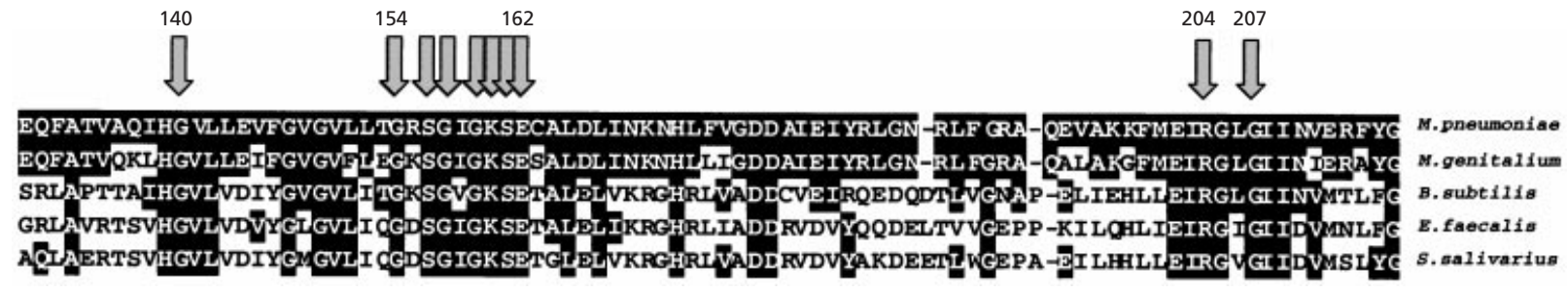

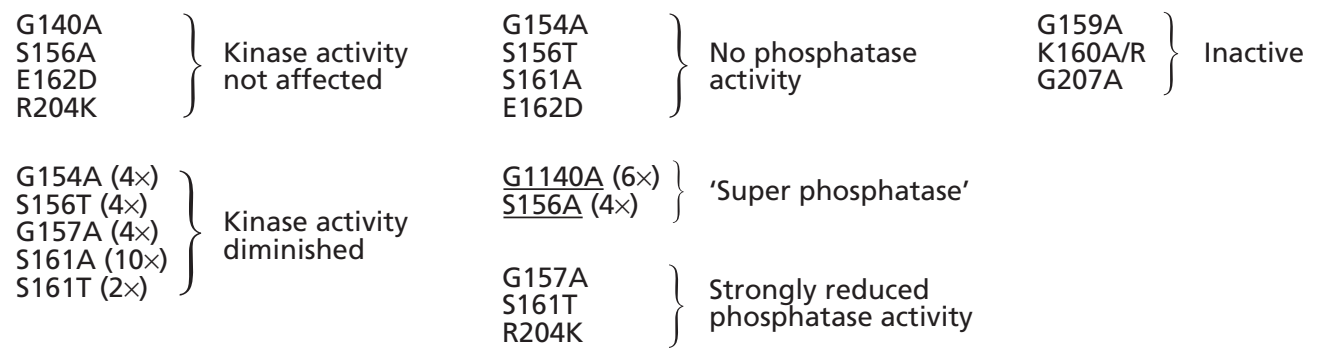

Fig. 5. Location of the mutations introduced in the $h p r K$ gene by site-directed mutagenesis. Alignment of the conserved regions of HPrK/P from M. pneumoniae (Himmelreich et al., 1996), M. genitalium (Fraser et al., 1995), B. subtilis (Galinier et al., 1998; Reizer et al., 1998), E. faecalis (Kravanja et al., 1999) and Streptococcus salivarius (Brochu \& Vadeboncoeur, 1999) containing the Walker A box nucleotide-binding motif and the HPrK/P signature sequence. Numbering corresponds to $M$. pneumoniae HPrK/P. Effects of the mutations as compared to the wild-type protein were grouped as follows: mutations which did not affect kinase activity, mutations which diminished kinase activity, mutations which led to complete loss of phosphatase activity, 'super phosphatases' which show even better phosphatase activity as compared to the wild-type, mutations which strongly reduced phosphatase activity and mutations which led to a complete loss of function.

This mutation, G140A, had no effect on kinase activity; however, the phosphatase activity was observed even at low concentrations of $P_{i}(1 \mathrm{mM})$.

Two mutations of the signature sequence were introduced and their effects studied. An R204K mutation affected only phosphatase activity, which was strongly reduced as compared to the wild-type protein. The G207A mutation completely abolished all activities of $\mathrm{HPrK} / \mathrm{P}$.

\section{DISCUSSION}

The regulation of carbon catabolism has been the subject of intensive studies in different groups of bacteria, such as the enteric bacteria and the low-GC Gram-positive bacteria with their model organisms, E. coli and $B$. subtilis, respectively (Stülke \& Hillen, 1999). These bacteria often have to cope with a scarcity of nutrients in their natural habitats. M. pneumoniae, in contrast, lives attached to mammalian cells and depends on the host for many nutrients. For these bacteria, nutrient limitation may thus be an exception rather than the rule. Yet, $\mathrm{HPr}$ and $\mathrm{HPrK} / \mathrm{P}$ are among the few regulatory proteins encoded in the genome of $M$. pneumoniae, suggesting that they serve a role in the control of carbon metabolism.

HPrK/P from B. subtilis is active as a phosphatase in the absence of any metabolites if $P_{i}$ is present. Kinase activity occurs only if the concentration of ATP is high $(>0.2 \mathrm{mM})$ and glycolytic intermediates such as FBP are present (Jault et al., 2000). Similarly, the enzymes from other low-GC Gram-positive bacteria are active as a kinase only at high ATP concentrations that indicate a good supply of nutrients (Kravanja et al., 1999; Brochu \& Vadeboncoeur, 1999; Dossonnet et al., 2000; Huynh et al., 2000). In contrast, M. pneumoniae HPrK/P exhibits an inverse mode of regulation: this enzyme needs $\mathrm{P}_{\mathrm{i}}$ for phosphatase activity, whereas the kinase activity occurs at ATP concentrations as low as $1 \mu \mathrm{M}$. Thus, this protein is by default a kinase rather than a phosphatase. M. pneumoniae HPrK/P phosphorylates HPr at Ser-46 as the standard reaction (see Figs 3 and 4). This may result in permanent carbon catabolite repression of genes required for the utilization of secondary carbon sources, and in controlled sugar uptake. This correlates well with the nutrient-rich environment of $M$. pneumoniae, in which there is no limitation of preferred sources of carbon and energy. On the other hand, the standard phosphatase activity of the B. subtilis $\mathrm{HPrK} / \mathrm{P}$ results in absence of catabolite repression as a standard regulatory mechanism in poor environments.

In the course of this study it turned out that $M$. pneumoniae $\mathrm{HPrK} / \mathrm{P}$ phosphorylated the cognate $\mathrm{HPr}$ much more efficiently than its counterpart from $B$. megaterium. This finding is in good agreement with the identification of specificity determinants required for the interaction between HPrK/P and HPr of M. capricolum. Residues 48, 49 and 51-53 of $\mathrm{HPr}$ are important for kinase-HPr recognition (Zhu et al., 1998). While the latter three residues are shared by the HPr sequences of M. pneumoniae and B. megaterium (Himmelreich et al., 
1996; Wagner et al., 2000), the former are not conserved and may be responsible for the weak phosphorylation of B. megaterium HPr by M. pneumoniae HPrK/P.

There are two strongly conserved sequence motifs in $\mathrm{HPrK} / \mathrm{P}$ : the potential ATP-binding site and the signature sequence. A mutational analysis of these sequences revealed that both motifs contain residues that are indispensable for the enzymic function of $\mathrm{HPrK} / \mathrm{P}$. The recent elucidation of the three-dimensional structure of L. case $i \mathrm{HPrK} / \mathrm{P}$ indicated that both motifs are located in close proximity (Fieulaine et al., 2001). The GKSE cluster in the ATP-binding site is most important for both kinase and phosphatase activities. Even conservative substitutions (G159A, K160R) result in complete inactivation. Similarly, a replacement at the corresponding position in B. subtilis and L. casei $\mathrm{HPrK} / \mathrm{P}$ (G158A and G160S, respectively) results in a strong decrease of kinase and abolition of phosphatase activity (Monedero et al., 2001; Hanson et al., 2002). The mutational separation of the enzymic activities is also observed with M. pneumoniae HPrK/P. The E162D substitution results in complete loss of phosphatase activity without affecting kinase activity. A corresponding mutation of L. casei $\mathrm{HPrK} / \mathrm{P}$ may have similar consequences, since the mutant strain exhibits constitutive catabolite repression indicative of constitutive phosphorylation of HPr and loss of dephosphorylation (Monedero et al., 2001). In HPrK/P of L. casei, amino acids of the KSE motif interact with $\mathrm{P}_{\mathrm{i}}$ (Fieulaine et al., 2001). Moreover, the phosphatase reaction was shown to be enzymically distinct from the kinase reaction for HPrK/P of L. casei (Monedero et al., 2001). Thus, the specific effect of mutations in this region on phosphatase activity may result from loss of $\mathrm{P}_{\mathrm{i}}$ binding. In contrast, the G140A and S156A mutant proteins exhibit normal kinase activity, but their phosphatase activity is strongly enhanced as compared to the wild-type protein. The fully conserved G207 residue of the signature sequence is essential for HPrK/P function in M. pneumoniae. The corresponding mutant of the B. subtilis enzyme exhibits very weak kinase and no phosphatase activity (Hanson et al., 2002). Of the mutations studied so far, no substitutions that reduce kinase activity without affecting phosphatase activity have been identified, whereas mutations abolishing phosphatase activity but allowing kinase activity have been found in M. pneumoniae, B. subtilis and L. casei (Monedero et al., 2001; Hanson et al., 2002). Interestingly, a mutational analysis of another bifunctional protein kinase/phosphatase from E. coli, isocitrate dehydrogenase kinase/phosphatase (IDH K/P), yielded results similar to those reported here: mutations of the ATP-binding site inactivate both kinase and phosphatase activities (Stueland et al., 1989). In addition, mutations selectively abolishing phosphatase activity were found (Ikeda et al., 1992).

To the best of our knowledge, HPrK/P is the first bifunctional enzyme for which opposing basal activities have been found in orthologues from different organisms. It will be interesting to analyse the structural basis of this phenomenon. The protein has been crystallized (Steinhauer et al., 2002) and analysis of the structure is under way.

\section{ACKNOWLEDGEMENTS}

We are grateful to R. Herrmann, University of Heidelberg, for the gift of cosmids containing the $p t s H$ and $h p r K$ genes. Frank Dyka is acknowledged for help with some experiments. We thank A. Wagner for providing us with purified $\mathrm{HPr}$ of $B$. megaterium. This work was supported by grants from the Deutsche Forschungsgemeinschaft and the Fonds der Chemischen Industrie to J.S. and W.H.

\section{REFERENCES}

Balasubramanian, S., Schneider, T., Gerstein, M. \& Regal, L. (2000). Proteomics of Mycoplasma genitalium: identification and characterization of unannotated and atypical proteins in a small model genome. Nucleic Acids Res 28, 3075-3082.

Bradford, M. M. (1976). A rapid and sensitive method for the quantitation of microgram quantities of protein utilizing the principle of protein-dye binding. Anal Biochem 72, 248-254.

Brochu, D. \& Vadeboncoeur, C. (1999). The $\mathrm{HPr}(\mathrm{Ser})$ kinase of Streptococcus salivarius: purification, properties, and cloning of the hprK gene. J Bacteriol 181, 709-717.

Deutscher, J., Küster, E., Bergstedt, U., Charrier, v. \& Hillen, w. (1995). Protein kinase-dependent $\mathrm{HPr} / \mathrm{CcpA}$ interaction links glycolytic activity to carbon catabolite repression in Grampositive bacteria. Mol Microbiol 15, 1049-1053.

Dossonnet, V., Monedero, V., Zagorec, M., Galinier, A., PerezMartinez, G. \& Deutscher, J. (2000). Phosphorylation of HPr by the bifunctional HPr Kinase/P-ser-HPr phosphatase from Lactobacillus casei controls catabolite repression and inducer exclusion but not inducer expulsion. J Bacteriol 182, 2582-2590.

Egan, W., Barile, M. \& Rottem, S. (1986). ${ }^{31}$ P-NMR studies of Mycoplasma gallisepticum cells using a continuous perfusion technique. FEBS Lett 204, 373-376.

Fieulaine, S., Morera, S., Poncet, S., Monedero, V., GueguenChaignon, V., Galinier, A., Janin, J., Deutscher, J. \& Nessler, S. (2001). X-ray structure of HPr kinase: a bacterial protein kinase with a P-loop nucleotide-binding domain. EMBO J 20, 39173927.

Fraser, C. M., Gocayne, J. D., White, O. \& 26 other authors (1995). The minimal gene complement of Mycoplasma genitalium. Science 270, 397-403.

Galinier, A., Haiech, J., Kilhoffer, M.-C., Jaquinod, M., Stülke, J., Deutscher, J. \& Martin-Verstraete, I. (1997). The Bacillus subtilis crh gene encodes a HPr-like protein involved in carbon catabolite repression. Proc Natl Acad Sci U S A 94, 8439-8444.

Galinier, A., Kravanja, M., Engelmann, R., Hengstenberg, W., Kilhoffer, M.-C., Deutscher, J. \& Haiech, J. (1998). New protein kinase and protein phosphatase families mediate signal transduction in bacterial catabolite repression. Proc Natl Acad Sci U S A 95, 1823-1828.

Hanson, K. G., Steinhauer, K., Reizer, J., Hillen, W. \& Stülke, J. (2002). HPr kinase/phosphatase of Bacillus subtilis: expression of the gene and effects of mutations on enzyme activity, growth and carbon catabolite repression. Microbiology 148, 1805-1811.

Himmelreich, R., Hilbert, H., Plagens, H., Pirkl, E., Li, B.-C. \& Herrmann, R. (1996). Complete sequence analysis of the genome of the bacterium Mycoplasma pneumoniae. Nucleic Acids Res 24, $4420-4449$. 
Himmelreich, R., Plagens, H., Hilbert, H., Reiner, B. \& Herrmann, R. (1997). Comparative analysis of the genomes of the bacteria Mycoplasma pneumoniae and Mycoplasma genitalium. Nucleic Acids Res 25, 701-712.

Hoischen, C., Dijkstra, A., Rottem, S., Reizer, J. \& Saier, M. H., Jr (1993). Presence of protein constituents of the gram-positive bacterial phosphotransferase regulatory system in Acholeplasma laidlawii. J Bacteriol 175, 6599-6604.

Hutchinson, C. A., III, Peterson, S. C., Gill, S. R., Cline, R. T., White, O., Fraser, C. M., Smith, H. O. \& Venter, J. C. (1999). Global transposon mutagenesis and a minimal mycoplasma genome. Science 286, 2165-2169.

Huynh, P. L., Jankovic, I., Schnell, N. F. \& Brückner, R. (2000). Characterization of an HPr kinase mutant of Staphylococcus xylosus. J Bacteriol 182, 1895-1902.

Ikeda, T. P., Houtz, E. \& LaPorte, D. C. (1992). Isocitrate dehydrogenase kinase/phosphatase: identification of mutations which selectively inhibit phosphatase activity. J Bacteriol $\mathbf{1 7 4}$ 1414-1416.

Jault, J. M., Fieulaine, S., Nessler, S., Gonzalo, P., Di Pietro, A., Deutscher, J. \& Galinier, A. (2000). The HPr kinase from Bacillus subtilis is a homo-oligomeric enzyme which exhibits strong positive cooperativity for nucleotide and fructose 1,6-bisphosphate binding. J Biol Chem 275, 1773-1780.

Kravanja, M., Engelmann, R., Dossonnet, V., Blüggel, M., Meyer, H. E., Frank, R., Galinier, A., Deutscher, J., Schnell, N. \& Hengstenberg, W. (1999). The hprK gene of Enterococcus faecalis encodes a novel bifunctional enzyme: the HPr kinase/ phosphatase. Mol Microbiol 31, 59-66.

Mason, P. W., Carbone, D. P., Cushman, R. A. \& Waggoner, A. S. (1981). The importance of inorganic phosphate in regulation of energy metabolism of Streptococcus lactis. J Biol Chem 256, 1861-1866.

Miles, R. J. (1992). Catabolism in mollicutes. J Gen Microbiol 138, 1773-1783.

Monedero, V., Poncet, S., Mijakovic, I., Fieulaine, S., Dossonnet, V., Martin-Verstraete, I., Nessler, S. \& Deutscher, J. (2001). Mutations lowering the phosphatase activity of HPr kinase/ phosphatase switch off carbon metabolism. EMBO J 20, 39283937.

Razin, S., Yogev, D. \& Naot, Y. (1998). Molecular biology and pathogenicity of mycoplasmas. Microbiol Mol Biol Rev 62, 1094-1156.

Reizer, J., Hoischen, C., Titgemeyer, F., Rivolta, C., Rabus, R., Stülke, J., Karamata, D., Saier, M. H., Jr \& Hillen, W. (1998). A novel protein kinase that controls carbon catabolite repression in bacteria. Mol Microbiol 27, 1157-1169.

Sambrook, J., Fritsch, E. F. \& Maniatis, T. (1989). Molecular Cloning: a Laboratory Manual, 2nd edn. Cold Spring Harbor, NY: Cold Spring Harbor Laboratory.
Saraste, M., Sibbald, P. R. \& Wittinghofer, A. (1990). The P-loop - a common motif in ATP- and GTP-binding proteins. Trends Biochem Sci 15, 430-434.

Schägger, H. \& von Jagow, G. (1987). Tricine-sodium dodecyl sulfate-polyacrylamide gel electrophoresis for the separation of proteins in the range from 1 to $100 \mathrm{kDa}$. Anal Biochem 166, 368-379.

Schirmer, F., Ehrt, S. \& Hillen, W. (1997). Expression, inducer spectrum, domain structure, and function of MopR, the regulator of phenol degradation in Acinetobacter calcoaceticus NCIB8250. J Bacteriol 179, 1329-1336.

Steinhauer, K., Allen, G. S., Hillen, W., Stülke, J. \& Brennan, R. G. (2002). Crystallization, preliminary $\mathrm{X}$-ray analysis and biophysical characterization of HPr kinase/phosphatase of $\mathrm{MycO}$ plasma pneumoniae. Acta Crystallogr Sect D 58, 515-518.

Stueland, C. S., Ikeda, T. P. \& LaPorte, D. C. (1989). Mutation of the predicted ATP binding site inactivates both activities of isocitrate dehydrogenase/phosphatase. J Biol Chem 264, 1377513779 .

Stülke, J. \& Hillen, W. (1999). Carbon catabolite repression in bacteria. Curr Opin Microbiol 2, 195-201.

Vertommen, D., Bertrand, L., Sontag, B., Di Pietro, A., Louckx, M. P., Vidal, H., Hue, L. \& Rider, M. H. (1996). The ATP-binding site in the 2-kinase domain of liver 6-phosphofructo-2-kinase/ fructose-2,6-bisphosphatase. J Biol Chem 271, 17875-17880.

Wagner, A., Küster-Schöck, E. \& Hillen, W. (2000). Sugar uptake and carbon catabolite repression in Bacillus megaterium strains with inactivated ptsHI. J Mol Microbiol Biotechnol 2, 587-592.

Walker, J. E., Saraste, M., Runswick, M. J. \& Gay, N. J. (1982). Distantly related sequences in the alpha- and beta-subunits of ATP synthase, myosin, kinases and other ATP-requiring enzymes and a common nucleotide binding fold. EMBO J 1, 945-951.

Wasinger, V. C., Pollack, J. D. \& Humphery-Smith, I. (2000). The proteome of Mycoplasma genitalium: Chaps-soluble component. Eur J Biochem 267, 1571-1582.

Weiner, J., III, Herrmann, R. \& Browning, G. F. (2000). Transcription in Mycoplasma pneumoniae. Nucleic Acids Res 28, 4488-4496.

Woese, C. R. (1987). Bacterial evolution. Microbiol Rev 51, 221-271.

Zhu, P.-P., Nosworthy, N., Ginsburg, A., Miyata, M., Seok, Y.-J. \& Peterkofsky, A. (1997). Expression, purification, and characterization of Enzyme IIA ${ }^{\text {gle }}$ of the phosphoenolpyruvate:sugar phosphotransferase system of Mycoplasma capricolum. Biochemistry 36, 6947-6953

Zhu, P.-P., Herzberg, O. \& Peterkofsky, A. (1998). Topography of the interaction of $\operatorname{HPr}(\mathrm{Ser})$ kinase with $\mathrm{HPr}$. Biochemistry 37, $11762-11770$

Received 12 March 2002; revised 27 June 2002; accepted 5 July 2002. 